\title{
Seasonal cues mediate host behaviour modification and cocoon polymorphism in Microplitis mediator (Hymenoptera: Braconidae)
}

\author{
Shu-PING LUO ${ }^{1,4}$, J.P. MICHAUD ${ }^{2}$, JiAn-Cheng LI ${ }^{3}$, Jing ZHANG ${ }^{1}$, XIAO-XIA LIU ${ }^{1 *}$ and QING-Wen ZHANG ${ }^{1 *}$ \\ ${ }^{1}$ Department of Entomology, China Agricultural University, Beijing, 100193, China \\ ${ }^{2}$ Department of Entomology, Kansas State University, Agricultural Research Center - Hays, Hays, Kansas, 67601, USA; \\ e-mail: jpmi@ksu.edu \\ ${ }^{3}$ Institute of Plant Protection, Hebei Academy of Agriculture and Forestry Sciences, Baoding 071001, China \\ ${ }^{4}$ State Key Laboratory for Biology of Plant Diseases and Insect Pest, Institute of Plant Protection, Chinese Academy \\ of Agricultural Sciences, Beijing 100193, China
}

Key words. Hymenoptera, Braconidae, Microplitis mediator, Lepidoptera, Noctuidae, Mythimna separata, photoperiod, host behaviour, pupation site selection, cocoon polymorphism, temperature

\begin{abstract}
Laboratory experiments were conducted to examine the effects of photoperiod and temperature on the pupation behaviour of the parasitoid, Microplitis mediator (Haliday) (Hymenoptera: Braconidae), parasitizing larvae of Mythimna separata Walker (Lepidoptera: Noctuidae). A combination of long photoperiod $(14+\mathrm{h} \mathrm{L})$ and warm temperatures $\left(20-24^{\circ} \mathrm{C}\right)$ caused parasitized caterpillars to climb to upper plant parts where the parasitoid produced a green, non-diapausing cocoon on a green leaf, initially retaining the dying caterpillar host as a protective covering. In contrast, short photoperiod $(8-10 \mathrm{~h} \mathrm{~L})$ and low temperature $\left(16-18^{\circ} \mathrm{C}\right)$ induced host caterpillars to descend the plant where the parasitoid produced a brown, diapausing cocoon either hanging by silk from a senescing leaf or simply lying on the soil, but without any continued association with the host. These findings illustrate the potential for seasonal environmental cues to simultaneously mediate diapause induction, cocoon polymorphism, and alternate forms of host behaviour modification in a hymenopterous parasitoid.
\end{abstract}

\section{INTRODUCTION}

Remarkable changes in behaviour have been observed in insects as a result of parasitism (Stamp 1981; Poulin, 1995; Eberhard, 2000; Ponton et al., 2006; Grosman et al., 2008). Many parasitoids, in particular, can induce dramatic alterations in the physiology and behaviour of their hosts before killing them (Brodeur \& McNeil, 1989; Godfray, 1994). Host behavioral manipulation is hypothesized to enhance parasitoid survival, either by inducing dispersal to a more favorable microhabitat or otherwise reducing exposure to predation or adverse physical conditions (Eberhard, 2000; Beckage, 2002). Presumably, the evolution of many successful parasitoid-host relationships have hinged on adaptative modification of host behaviour by the parasitoid. Typically, this involves reprogramming host neuro-endocrine systems to alter host hormone titres (Beckage \& Gelman, 2004) and interfering with host immune responses (Beckage, 2002; Cole et al., 2002) thus disrupting normal host development, morphology and behaviour (e.g., Lawrence, 1986; Adamo \& Shoemaker, 2000; Adamo, 2005).

Diapause is a life history adaptation that affords many insect species a mechanism for surviving adverse environmental conditions, typically extremes of temperature that are seasonally predictable and associated with a lack of food (Tauber \& Tauber, 1976; Danks, 1987). By passing unsuitable periods in a state of dormancy, insect populations are able to remain year-round in environments that would otherwise be uninhabitable. Although many insects diapause as adults, diapause via arrestment of development in an immature stage is often associated with the production of specific structures such as cocoons and hibernacula that can serve to protect and insulate dormant insects. Photoperiod and temperature are among the most reliable environmental cues for induction of insect diapause (Denlinger, 2002; Li et al., 2008). Specific developmental stages are typically light-sensitive (Brodeur \& McNeil, 1989) and immature parasitoids are able to measure daylength from within their hosts (Mehrnejad \& Copeland, 2005; Rasekh et al., 2010).

The parasitic wasp Microplitis mediator (Haliday) (Hymenoptera: Braconidae) is a solitary larval endoparasitoid that is widely distributed in the Palaearctic region (Mason et al., 2001). In China, it is a significant source of mortality for several important agricultural pests including Mythimna separata (Walker, 1865) and the cotton bollworm, Helicoverpa armigera (Hübner, 1805) (Lepidoptera: Noctuidae) (Liu et al., 2005) and has been successfully mass-reared in the laboratory. Natural rates of $H$. armigera parasitism in cotton fields average around $8.9 \%$ (range $=4.4-12.9 \%$, Fang et al., 2000) and have been raised to $38.5-65.6 \%$ by augmentation biological control programs (Li et al., 2005). Parasitized M. separata larvae die as mature $M$. mediator larvae emerge; the latter produce either a brown cocoon when reared under

\footnotetext{
* Corresponding authors; e-mails: zhangqingwen@263.net; xxliu@hotmail.com
} 
diapause-inducing conditions, or a green one under nondiapause conditions. Parasitoid pupation takes place above ground in green cocoons that adhere quite tightly to plant leaves, whereas brown cocoons are attached with only a few silken strands and are easily dislodged to the soil surface. In contrast, unparasitized $M$. separata larvae pupate in earthen cells they excavate in the soil at a depth of about $2.0 \mathrm{~cm}$. Although adults and late instar larvae sometimes overwinter, most overwintering occurs in the pupal stage at depths of $3.5-5.0 \mathrm{~cm}$.

Based on preliminary observations, we hypothesized that $M$. mediator larvae are able to use thermal and photoperiodic cues perceived within the body of their hosts to modify host behaviour along one of two divergent paths so as to optimize both cocoon morphology and pupation site for either diapause or uninterrupted development. In the present study, we manipulated these extrinsic environmental factors to clarify the role of temperature and photoperiod on diapause induction and observed pupal site selection by $M$. mediator-parasitized $M$. separata larvae on corn plants and in cage settings.

\section{MATERIAL AND METHODS}

\section{Insect colonies}

Mythimna separata larvae were obtained from a stock culture maintained by the Hebei Plant Protection Institute, China, and reared at $26 \pm 1{ }^{\circ} \mathrm{C}$ (mean $\pm \mathrm{SE}$ ) under 14L : 10D photoperiod and $65 \% \mathrm{RH}$ on an artificial diet composed of wheat germ and macerated seedling corn leaves $(\mathrm{Bi}, 1981)$. A colony of $M$. mediator was established from adult parasitoids that emerged from $H$. armigera larvae collected in a cotton field in Baoding, Heibei, China, during the summer in 2007. The colony was then reared in the laboratory on $M$. separata continuously for eight generations under the same physical conditions as the host, except that adult wasps were held at $19 \pm 1{ }^{\circ} \mathrm{C}$. Hosts were parasitized by placing approximately 50 two to four day-old mated females of $M$. mediator in a cage $(30.0 \times 40.0 \times 25.0 \mathrm{~cm})$ containing 1,000 late first and early second instars of $M$. separata on corn leaves with $10 \%$ honey solution provided on absorbent cotton and refreshed daily. After a $24 \mathrm{~h}$ exposure period, host larvae were transferred to individual mesh bags $(25.0 \times 25.0 \times$ $5.0 \mathrm{~cm}$ ) containing diet (corn leaves) until parasitoid cocoons formed. Newly emerged adult parasitoids were placed in a ventilated acrylic cage $(30.0 \times 30.0 \times 40.0 \mathrm{~cm})$ with diet $(10 \%$ honey solution) and mated females were used for experiments when they were two days old.

\section{Plants}

Corn was planted in flowerpots $(20.0 \mathrm{~cm}$ diam. $\times 18.0 \mathrm{~cm})$ in a greenhouse at $26 \pm 2{ }^{\circ} \mathrm{C}, 14 \mathrm{~L}: 10 \mathrm{D}$ and irrigated every three days. A week prior to use in the experiments, when the corn plants were about $70 \mathrm{~cm}$ high, flowerpots were moved outside under natural conditions.

\section{Diapause induction}

Second instars of $M$. separata larvae ( $\mathrm{n}=30$ per parasitoid) were exposed to a mated, two day-old $M$. mediator female in a glass cylinder $(8.0 \mathrm{~cm}$ diameter $\times 10.0 \mathrm{~cm}$ height $)$ covered with thick black fabric and containing fresh corn leaves for the host and a $10 \%$ honey solution on a cotton ball for the parasitoid. After $24 \mathrm{~h}$ of exposure, the parasitoid was removed and the $M$. separata larvae transferred to a mesh bag $(25.0 \times 25.0 \times 5.0 \mathrm{~cm})$ containing corn leaves and incubated in a growth chamber (LRH-250-G, Ningbo Jiangnan Equipment Factory, Zhejiang,

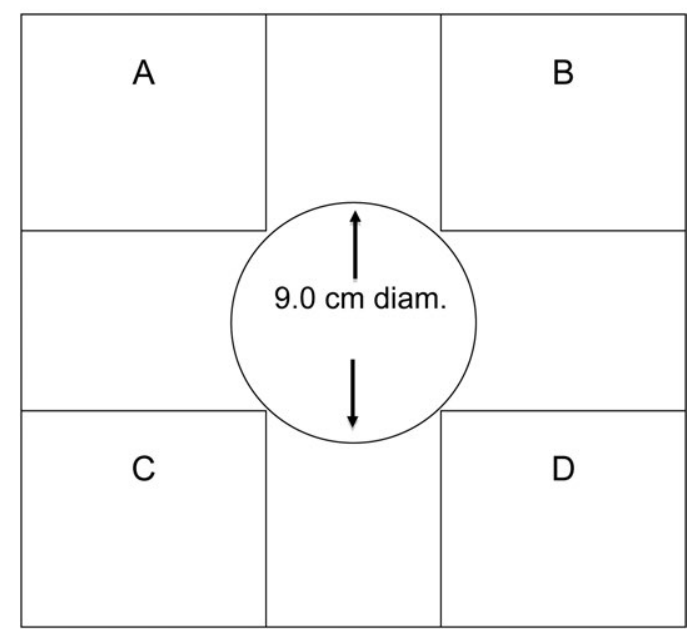

Fig. 1. Diagram depicting subdivision of cage bottom used for pupation site selection experiments.

China). In order to determine the set of conditions producing the maximum percentage of diapausing pupae, larvae were incubated at one of three constant temperatures $\left(16.0^{\circ} \mathrm{C}, 18.0^{\circ} \mathrm{C}\right.$ or $20.0^{\circ} \mathrm{C}$ ) under a series of photoperiods ranging from continuous dark to continuous light in two hour increments; (1) L0: D24, (2) L2: D22, (3) L4: D20, (4) L6: D18, (5) L8: D16, (6) L10: D14, (7) L12: D12, (8) L14: D10, (9) L16: D8, (10) L18: D6, (11) L20: D4, (12) L22: D2 and (13) L24: D0. Each treatment combination of temperature and photoperiod was replicated five times with approximately $100 \mathrm{M}$. separata larvae in each bag for a total of 39 individual treatments.

\section{Pupation site selection on corn plants}

Three day-old mated M. mediator females were each provided second instar M. separata larvae ( $\mathrm{n} \sim 30$ per wasp) for 24 $\mathrm{h}$ (as above). Wasps were then removed and the larvae were transferred to mesh bags with diet. Based on the results of the previous experiment, parasitized larvae were divided into two groups; 250 larvae were reared under non-diapausing conditions $\left(26 \pm 1{ }^{\circ} \mathrm{C}, 14 \mathrm{~L}: 10 \mathrm{D}\right.$ photoperiod) and another 250 were reared under conditions optimal for diapause induction $\left(16 \pm 1^{\circ} \mathrm{C}, 10 \mathrm{~L}\right.$ : 14D photoperiod). Larvae reared under non-diapausing conditions were held for 9 days on diet before transfer to potted corn plants for pupation under the same physical conditions ( $\mathrm{n}=50$ larvae per plant, with five replications). Larvae reared under diapausing conditions were held for 20 days on diet before transfer to potted corn plants under identical physical conditions ( $\mathrm{n}=50$ larvae per plant, with five replications). Observations were recorded once all parasitoids pupated. The pupation site of parasitoids was categorized as either (1) a green corn leaf, (2) a senescent yellow or grey corn leaf, and (3) on the soil surface; parasitoid emergence was tallied.

\section{Pupation site selection in cages}

Larvae of $M$. separata parasitized by $M$. mediator were reared for 9 days under normal (non-diapausing) conditions (as above), and host larvae were transferred to acrylic glass cages $(40.0 \times$ $40.0 \times 35.0 \mathrm{~cm}, \mathrm{n}=80$ per cage, five replicates per treatment $)$. The bottom of the cage $(40.0 \times 40.0 \mathrm{~cm})$ was divided into five sections: a $9.0 \mathrm{~cm}$ diameter circle in the center of cage surrounded by four squares $(17.0 \times 17.0 \mathrm{~cm})$ at the corners of the cage (Fig. 1). Two diagonally opposite squares contained 10-15 fresh green corn leaves (replaced daily) whereas the other two 

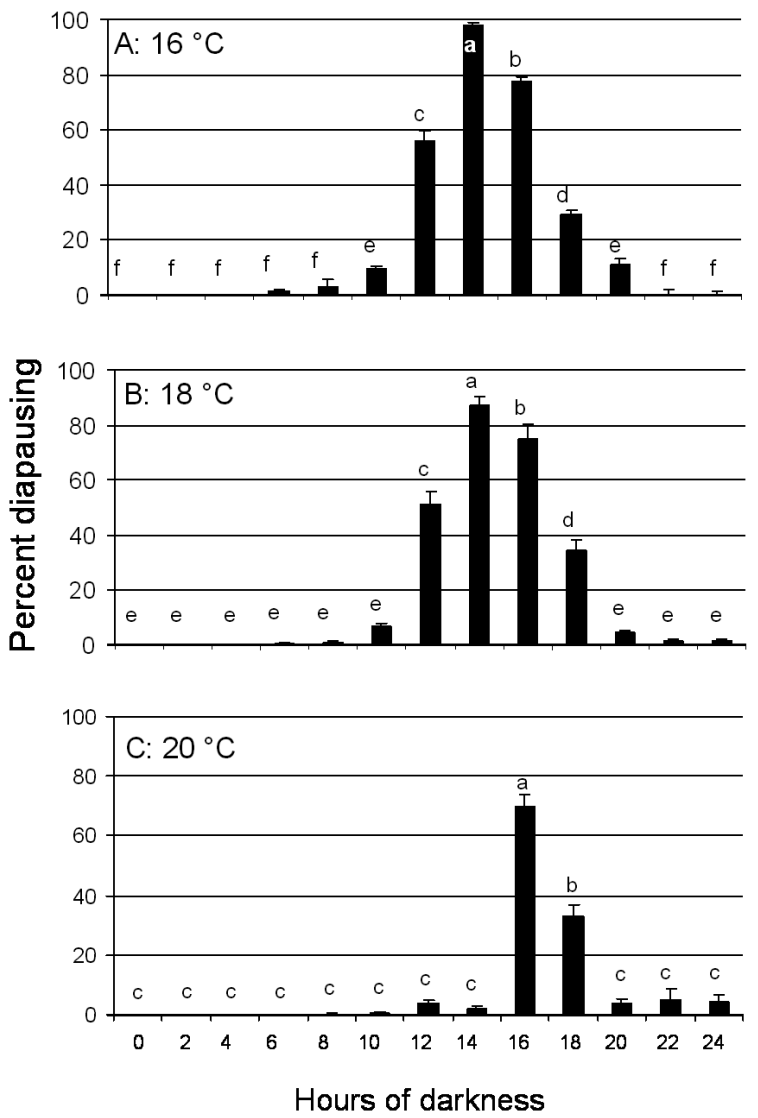

Fig. 2. Percentages of $M$. mediator larvae (+ SE) producing diapausing pupae when reared under different daylengths at three different constant temperatures $\left(20^{\circ} \mathrm{C}: \mathrm{n}=387-658\right.$ pupae $/$ treatment, mean $=478 ; 18^{\circ} \mathrm{C}: \mathrm{n}=389-1001$ pupae $/$ treatment, mean $=557 ; 16^{\circ} \mathrm{C}: 437-915$ pupae $/$ treatment, mean $=581$ ). Columns bearing the same letter were not significantly different from others within the same temperature treatment (LSD, $\alpha=$ $0.05)$.

contained 10-15 senescent yellowing or grey corn leaves. A total of 80 parasitized larvae were then placed within the central circle in each cage so that the larvae could freely select pupation sites. In a second series of treatments, parasitized $M$. separata larvae were reared for 20 days under diapause-inducing conditions (as described above) and then transferred to cages (as above, 80 larvae per cage, five replications) except that diapause-inducing conditions were sustained. Pupation site selection and emergence of parasitoids was subsequently recorded.

\section{Statistical analysis}

Data on the percentage of insects diapausing in the diapause induction experiment were analyzed using a two-way factorial ANOVA followed by Fisher's LSD test to separate means (SAS, 2004) and data from the oviposition site selection experiments on potted corn and in cages were analyzed by one-way ANOVA followed by Fisher's LSD test.

\section{RESULTS}

\section{Diapause induction}

The two-way ANOVA was significant overall $(\mathrm{F}=$ 175.11; $\mathrm{df}=38,156 ; P<0.001)$ and revealed main effects of both temperature regime $(\mathrm{F}=138.13 ; \mathrm{df}=38,156 ; P<$ $0.001)$ and photoperiod $(\mathrm{F}=424.13$; df $=38,156 ; P<$

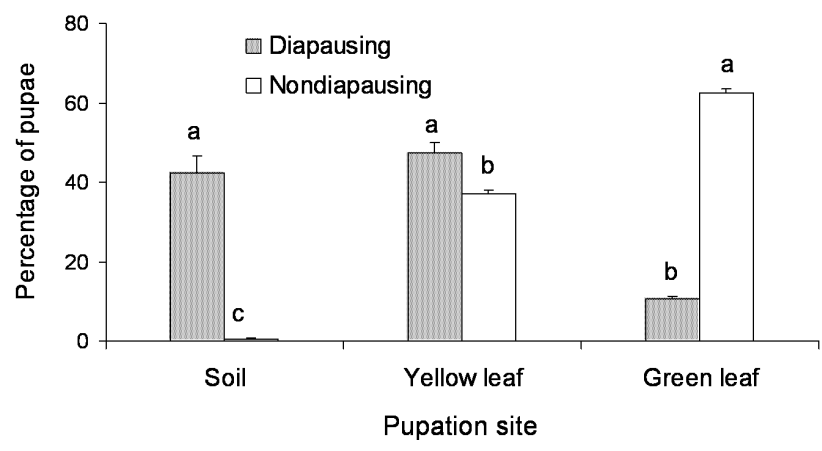

Fig. 3. Percentage (+ SE) of diapausing (shaded columns, $\mathrm{n}=$ 250) and nodiapausing (open columns, $\mathrm{n}=250$ ) M. mediator larvae selecting one of three alternative pupation sites on potted maize plants. Columns bearing the same letter were not significantly different from others of the same larval type (LSD, $\alpha=$ $0.05)$.

$0.001)$, with a significant interaction between these two independent variables $(\mathrm{F}=53.68 ; \mathrm{df}=24,156 ; P<$ $0.001)$. Ignoring daylength, both 16 and $18^{\circ} \mathrm{C}$ yielded a higher proportion of diapausing parasitoid pupae than did $20^{\circ} \mathrm{C}(\mathrm{F}=4.06 ; \mathrm{df}=2,192 ; \mathrm{P}=0.019 ;$ LSD test, $\alpha=$ $0.05)$. The highest percentage of diapausing individuals (98.1\%) was obtained with $14 \mathrm{~h}$ of darkness at a temperature of $16^{\circ} \mathrm{C}$ (Fig. 2A); these conditions were therefore used to produce diapausing larvae for pupation site selection experiments. Fourteen hours of darkness also produced the highest percentage of diapausing individuals at $18^{\circ} \mathrm{C}$ (Fig. 2B), but $16 \mathrm{~h}$ was required to obtain the maximum at $20^{\circ} \mathrm{C}$ (Fig. $2 \mathrm{C}$ ).

\section{Pupation site selection on corn plants}

Brown, diapausing cocoons formed mainly on dry soil and senescent, yellow leaves, with significantly fewer forming on green leaves $(\mathrm{F}=12.15 ; \mathrm{df}=2,18 ; P<0.001)$ whereas green, non-diapausing cocoons formed significantly more often on green than on withered or yellow leaves and were observed only rarely on the soil ( $\mathrm{F}=$ 4.18, df = 2,18; $P<0.05$; Fig. 3).

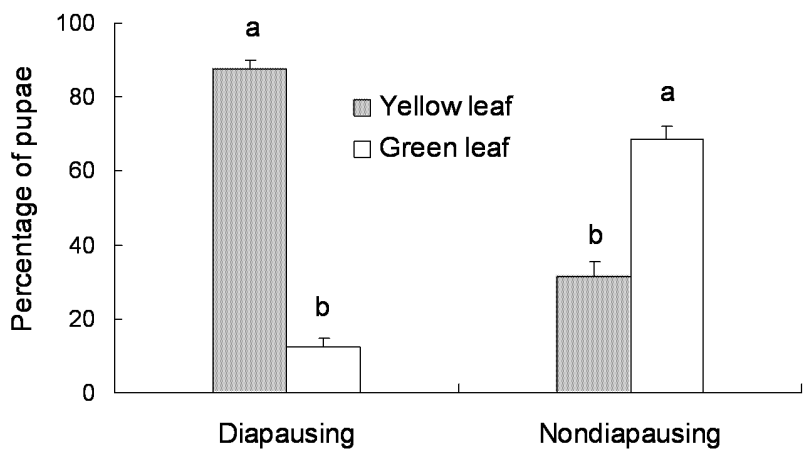

Fig. 4. Percentage $(+$ SE) of diapausing $(n=400)$ and nodiapausing $(\mathrm{n}=400) M$. mediator larvae selecting either green or yellow/senescent leaves for pupation in cages. Columns bearing the same letter were not significantly different from others of the same larval type (LSD, $\alpha=0.05$ ). 


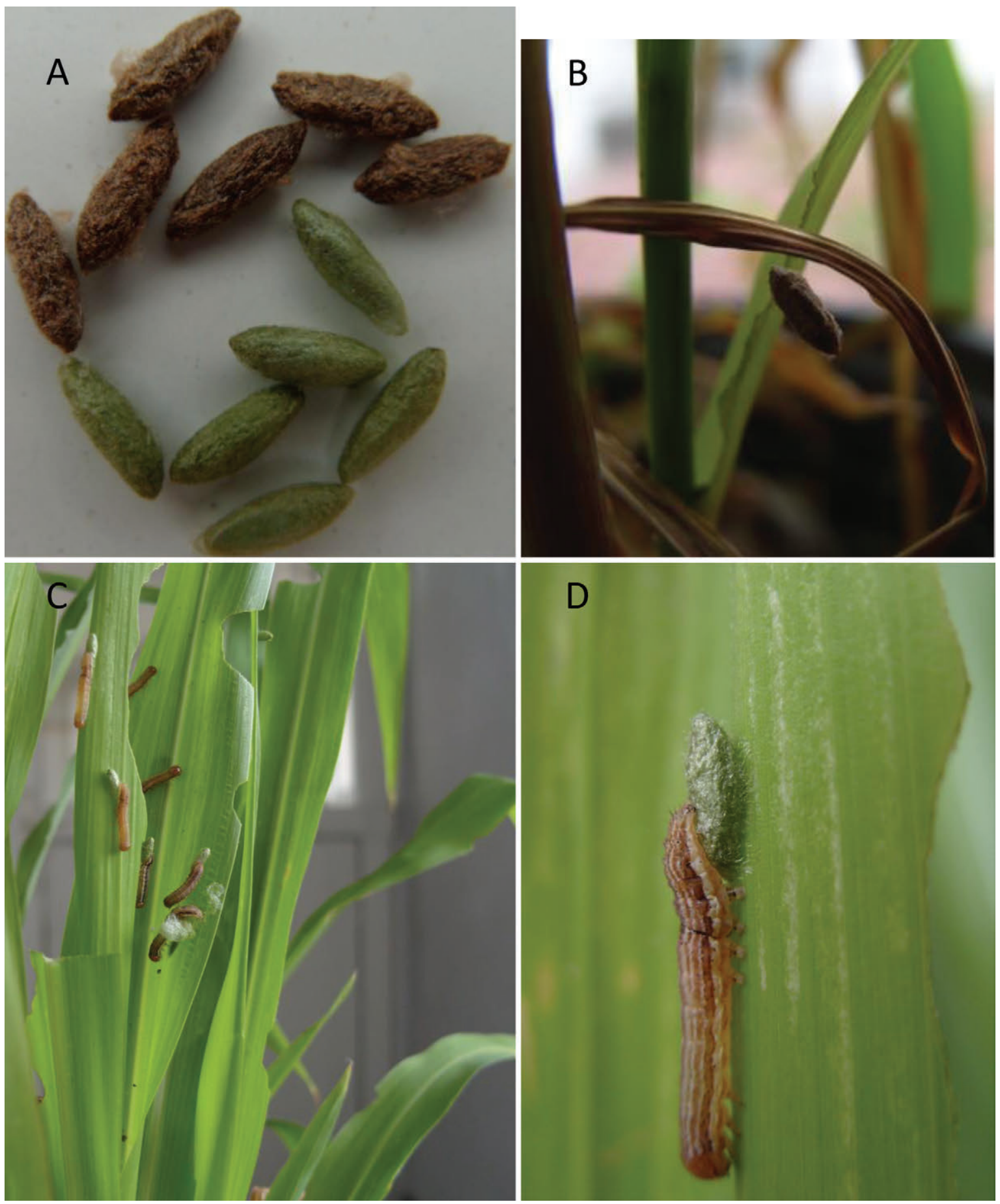

Fig. 5. A - diapausing (brown) and non-diapausing (green) cocoons of M. mediator; B - diapausing cocoons attached to senescent corn leaf; $\mathrm{C}$ - nondiapausing cocoons attached to green leaves; D - closeup of nondiapausing cocoons partially covered by body of dying host larva.

\section{Pupation site selection in cages}

Significantly more brown, diapausing cocoons formed on dry or senescing yellow maize leaves than on green leaves $(\mathrm{F}=465.75 ; \mathrm{df}=1,8 ; P<0.001)$, whereas green, non-diapausing cocoons formed significantly more often on fresh green leaves $(\mathrm{F}=51.76 ; \mathrm{df}=1,8 ; P<0.001 ;$ Fig. $4)$.

\section{DISCUSSION}

Many animals exhibit altered behaviour when infected by parasites (Moore, 1995, 2002; Cezilly \& PerrotMinnot, 2005; Thomas et al., 2005) and arthropods provide various examples of host behaviour manipulation (Fritz, 1982; Godfray, 1994; Beckers \& Wagner, 2011). These include altered patterns of web spinning in spiders (Eberhard, 2001), increasingly submissive behaviour (Libersat et al., 2009), suicidal behaviour (McAllister \& 
Roitberg, 1987; Biron et al., 2005), induced defensive behaviours (Ponton et al., 2006; Grosman et al., 2008), use of the host body as a defensive shield (Brodeur \& Vet, 1994) and orientation to safe pupation sites (Brodeur \& McNeil, 1992; Eberhard, 2000; Henne \& Johnson, 2007). Work has also begun to elaborate the neuronal basis for certain aspects of host manipulation (Libersat et al., 2009).

Larvae of $M$. mediator altered the behaviour of their host larvae and selected pupation sites that varied with the developmental fate of their pupae. Nondiapausing larvae oriented their hosts to growing leaves on upper plant parts; since higher ambient temperatures are likely to prevail higher up on the plant, this may serve to increase the rate of their development. However, growing leaves are more likely to bear actively feeding herbivores than are senescing leaves, and thus likely to be more intensively searched by foraging predators and hyperparasitoids. Notably, nondiapausing pupal cocoons assumed a green coloration, ostensibly to camoflage them on growing leaves of similar colour (Fig. 5C). Although such cocoons initially remain partially covered with the dying bodies of their hosts (Fig. 5C, D), it is not clear whether this phenomenon has any adaptive significance. The host caterpillar may live for a number of days; while alive, it remains on or near the parasitoid cocoon, but once dead, it is easly dislodged. However, other parasitoids regularly retain the dead body of their host as a cloak during pupation, apparently as a form of physical shelter or to reduce their risk of predation. For example, mature larvae of the coccinellid endoparasitoid Dinocampus coccinellae (Schrank, 1802), upon emergence from the host, spin a cocoon that retains the host exoskeleton enmeshed on its surface (Balduf, 1926).

In contrast to directly developing individuals, developmental rate is not a priority for diapausing parasitoid pupae; these must survive the winter on plant residues or soil to emerge the following spring. Consequently, diapausing pupae are likely safer on the soil or on plant parts that are dying or dead, their cocoons assuming a brown coloration that is consistent with the color of these substrates (Fig. 5A, B). It seems unlikely that hyperparasitism is a force driving this divergence in pupation behaviour, since hyperparasitoids would presumably exploit both diapausing and nondiapausing parasitoids. In addition, we have not yet observed any hyperparasitism in our collections of $M$. mediator from cotton fields. (Pivnick, 1993) found that $M$. mediator parasitizing Mamestra configurata (Walker) in Canada also changed host behaviour, but caused most parasitoid pupae to form on leaf litter, although a significantly higher proportion of nondiapausing larvae pupated on the plant; however, there was also no indication of divergent cocoon coloration. These disparities with our results may be due to a combination of regional differences in the parasitoid populations and their distinct interactions with different host species.

Certain species of the genus Asobara alter the behaviour of their drosphilid hosts to influence pupation height, which may affect exposure to humidity and propensity to diapause (Seyahooei et al., 2009). The observed pattern of pupation site selection on plants by $M$. mediator might be partially explained by a positive gravitropic response in diapausing parasitoid larvae and a negative gravitropic response in nondiapausing ones. However, the results of the cage experiments largely negate this explanation as these larvae oriented along a horizontal axis toward leaves that matched the coloration of the parasitoid pupa about to form, implicating a visual response to the pupation substrate, rather than a response to gravity.

The primary cue for diapause in $M$. mediator appeared to be short day length, as no diapausing larvae were obtained under long day conditions. However, the strength of diapause induction was enhanced by low temperature and increasingly shorter days were required to elicit the response as temperatures approached $20^{\circ} \mathrm{C}$ (Fig. 2), consistent with previous observations ( $\mathrm{Li}$ et al., 2008). It seems plausible that diapausing parasitoid pupae face different mortality risks on the soil versus on a dead plant and that variation in the relative importance of these factors could maintain a polymorphism with respect to selection of these two sites, respectively. It has also been suggested that some abnormal or altered behaviour expressed by parasitized hosts may simply reflect pathology or "sickness" (e.g., Franz \& Kurtz, 2002; Poulin, 2010). For example, the above-ground distribution of parasitized $M$. separata larvae in the present study may simply result from a loss of their normal ability to burrow in the soil; however, this would not explain the divergent locations of those containing diapausing and non-diapausing parasitoids. To further test these ideas, future field experiments could attach diapausing pupal cocoons to upper plant parts and compare their predation rate to those attached to lower plant parts or placed on the soil. Likewise, non-diapausing cocoons could be placed on lower plant parts and the soil and their developmental rate and survival compared to those forming normally on leaves, with and without host cadavers covering them.

ACKNOWLEDGMENTS. We thank the Institute of Plant Protection, Hebei Academy of Agricultural Sciences for their support. We are grateful to Ziyun Lu (Institute of Plant Protection, Hebei Academy of Agricultural Sciences) and Yanfang Pei (Changjiang University) for help with experiments. This work was funded by National Natural Science Foundation of China grant No. 31101444.

\section{REFERENCES}

AdAmo S.A. 2005: Parasitic suppression of feeding in the tobacco hornworm, Manduca sexta: Parallels with feeding depression after an immune challenge. - Arch. Insect Biochem. Physiol. 60: 185-197.

AdAmo S.A. \& ShoemaKer K.L. 2000: Effects of parasitism on the octopamine content of the central nervous system of Manduca sexta: a possible mechanism underlying host behavioural change. - Can. J. Zool. 78: 1580-1587.

Balduf W.V. 1926: The bionomics of Dinocampus coccinellae Schrank. - Ann. Entomol. Soc. Am. 19: 465-498.

BeckAGE N.E. 2002: Parasite- and pathogen-mediated manipulation of host behaviour. In Pfaff D., Arnold A., Etgen A., Fahr- 
bach S. \& Rubin R. (eds): Hormones, Brain and Behaviour. Academic Press, San Diego, pp. 281-315.

Beckage N.E. \& Gelman D.B. 2004: Wasp parasitoid disruption of host development: implications of new biologically based strategies for insect control. - Annu. Rev. Entomol. 49: 299-330.

BECKERS O.M. \& WAGNER W.E. JR. 2011: Male field crickets infested by parasitoid flies express phenotypes that may benefit the parasitoids. - Anim. Behav. 82: 1151-1157.

Bı F.C. 1981: A new artificial diet of Mythimna separata (Walker) (Lepidoptera: Noctuidae). - Acta Entomol. Sin. 124: 379-383.

Biron D.G., Joly C., Galeotti N., Ponton F. \& Marche L. 2005: The proteomics: a new prospect for studying parasitic manipulation. - Behav. Process. 68: 249-253.

BRodeur J. \& MCNeIL J.N. 1989: Seasonal microhabitat selection by an endoparasitoid through adaptive modification of host behaviour. - Science 244: 226-228.

BRodEur J. \& MCNEIL J.N. 1992: Host behaviour modification by the endoparasitoid Aphidius nigripes: A strategy to reduce hyperparasitism. - Ecol. Entomol. 17: 97-104.

BRODEUR J. \& Vet L.E.M. 1994: Usurpation of host behaviour by a parasitic wasp. - Anim. Behav. 48: 187-192.

Cezilly F. \& Perrot-Minnot M.J. 2005: Studying adaptive changes in the behaviour of infected hosts: a long and winding road. - Behav. Process. 68: 223-228.

Cole T.J., Beckage N.E., Tan F.F., SRinivasan A. \& RamasWAMY S.B. 2002: Parasitoid-host endocrine relations: selfreliance or co-optation? - Insect Biochem. Mol. Biol. 32: $1673-1679$

Danks H.V. 1987: Insect Dormancy: An Ecological Perspective. Biological Survey of Canada (Terrestrial Arthropods), Ottawa, ix +439 pp.

Denlinger D.L. 2002: Regulation of diapause. - Annu. Rev. Entomol. 47: 93-122.

EBERHARD W.G. 2000: Spider manipulation by a wasp larva. Nature 406: 255-256.

EBERHARD W.G. 2001: Under the influence: webs and building behaviour of Plesiometa argyra (Aranea, Tetragnathidae) when parasitized by Hymenoepimecis argyraphaga (Hymenoptera, Ichneumonidae). - J. Arachnol. 29: 354-366.

FAng H.Y., Zheng B.Z., Wang J.J., Yang X.Y. \& Tan H.Y. 2000: Occurrence of Microplitis mediator in transgenic $\mathrm{Bt}$ cotton field. - China Cotton 37: 29.

Franz K. \& KURTZ J. 2002: Altered host behaviour: manipulation or energy depletion in tapeworm-infected copepods? Parasitology 125: 187-196.

FrITZ R.S. 1982: Selection for host modification by insect parasitoids. - Evolution 36: 283-288.

Godfray H.J.C. 1994: Parasitoids: Behavioural and Evolutionary Ecology. Princeton University Press, Princeton, NJ, $473 \mathrm{pp}$.

Grosman A.H., Janssen A., De Brito E.F., Cordeiro E.G., Colares F., Fonseca J.O., Lima E.R., Pallini A. \& Sabelis M.W. 2008: Parasitoid increases survival of its pupae by inducing hosts to fight predators. - PLoS One 3: e2276.

HenNe D.C. \& Johnson S.J. 2007: Zombie fire ant workers: behavior controlled by decapitating fly parasitoids. Insectes Soc. 54: 150-153.

LAWRENCE P.O. 1986: Host-parasite hormonal interactions: An overview. - J. Insect Physiol. 32: 295-298.

Li J.C., Yan F.M., Coudron T.A., Pan W.L., Zhang X.F., Liu X.X. \& Zhang Q.W. 2005: Field release of the parasitoid Microplitis mediator (Hymenoptera: Braconidae) for control of Helicoverpa armigera (Lepidoptera: Noctuidae) in cotton fields in Northwestern China's Xinjiang province. - Environ. Entomol. 35: 694-699.

Li W.X., Li J.C., Coudron T.A., Lu Z.Y., PAN W.L., Liu X.X. \& ZHANG Q.W. 2008: Role of photoperiod and temperature in diapause induction of the endoparasitoid wasp Microplitis mediator (Hymenoptera: Braconidae). - Ann. Entomol. Soc. Am. 101: 613-618.

Libersat F., Delago A. \& Gal R. 2009: Manipulation of host behavior by parasitic insects and insect parasites. - Annu. Rev. Entomol. 54: 189-207.

Liu X.X., Zhang Q.W., Zhao J.Z., Li J.C., Xu B.L. \& Ma X.M. 2005: Effects of Bt transgenic cotton lines on the cotton bollworm parasitoid Microplitis mediator in the laboratory. Biol. Contr. 35: 134-141.

Mason P.G., ERLandson M.A. \& Youngs B.J. 2001: Effects of parasitism by Banchus flavescens (Hymenoptera: Ichneumonidae) and Microplitis mediator (Hymenoptera: Braconidae) on the bertha armyworm, Mamestra configurata (Lepidoptera: Noctuidae). - J. Hymenopt. Res. 10: 81-90.

McAllister M.K. \& RoItberg B.D. 1987: Adaptive suicidal behavior in pea aphids. - Nature 328: 797-799.

Mehrnejad M.R. \& Copland M.J.W. 2005: Diapause strategy in the parasitoid Psyllaephagus pistaciae. - Entomol. Exp. Appl. 116: 109-114.

MoORe J. 1995: The behaviour of parasitized animals. - Bioscience 45: 89-96.

Moore J. 2002: Parasites and the Behavior of Animals. Oxford Series in Ecology and Evolution. Oxford University Press, Oxford, $338 \mathrm{pp}$.

Pivnick K.A. 1993: Diapause initiation and pupation site selection of the Braconid parasitoid Microplitis mediator (Haliday) a case of manipulation of host behaviour. - Can. Entomol. 125: $825-830$.

Ponton F., Lebarbenchon C., Lefèvre T., Biron D.G., Dunean D., Hughes D.P. \& Thomas F. 2006: Parasitology: parasite survives predation on its host. - Nature 440: 756.

Poulin R. 1995: "Adaptive" changes in the behaviour of parasitized animals: A critical review. - Int. J. Parasitol. 25: 1371-1383.

Poulin R. 2010: Parasite manipulation of host behavior: An update and frequently asked questions. - Adv. Study Behav. 41: 151-186.

Rasekh R., Michaud J.P., Allahyari H. \& Sabahu Q. 2010: The foraging behaviour of Lysiphlebus fabarum (Marshall), a thelytokous parasitoid of the black bean aphid in Iran. - $J$. Insect Behav. 23: 165-179.

SAS Institute 2004: SAS ${ }^{\circledR}$ User's Guide: Statistics. SAS Institute, Cary, NC.

Seyahooei M.A., Kraaijeveld-Smit F.J.L., Kraaijeveld K., Crooljmans J.B.M., Van Dooren T.J.M. \& Van Alphen J.J.M. 2009: Closely related parasitoids induce different pupation and foraging responses in Drosophila larvae. - Oikos 118: $1148-1157$.

STAMP N.E. 1981: Behaviour of parasitized aposematic caterpillars - advantageous to the parasitoid or the host? - Am. Nat. 118: $715-725$.

TAUBER M.J. \& TAUBER C.A. 1976: Insect seasonality: Diapause maintenance, termination and postdiapause development. Annu. Rev. Entomol. 21: 81-107.

Thomas F., Adamo S. \& Moore J. 2005: Parasitic manipulation: where are we and where should we go? Behav. Process. 68: 185-199.

Received October 15, 2012; revised and accepted November 27, 2012 